\title{
ÓCIO AO LONGO DA VIDA \\ As potencialidades dos itinerários de ócio para a promoção do desenvolvimento humano*6
}

\author{
María Jesús Monteagudo \\ Universidade de Deusto, Espanha \\ Jaime Cuenca \\ Universidade de Deusto, Espanha \\ Fernando Bayón \\ Universidade de Deusto, Espanha \\ Douglas A. Kleiber \\ Universidade da Geórgia, Estados Unidos da América
}

\begin{abstract}
Resumo: Atualmente, mais do que nunca, investir no futuro é investir nas pessoas. Num período de crise profunda, não só de economia mas também de valores, o ócio é descrito como uma das poucas áreas da vida em que as pessoas encontram um espaço para a expressão e para o crescimento pessoal através da escolha e do envolvimento livre nas coisas de que gostam e que os redefine como indivíduos. No entanto, estes potenciais não surgem espontaneamente, senão como consequência de um processo vital, identificado como itinerário de ócio, através do qual as pessoas podem ir cultivando um horizonte cada vez mais complexo e cheio de necessidades, expectativas e benefícios que eles querem alcançar através do ócio. Com base nos resultados de um estudo de caso focado no grupo de idosos da Região Autónoma do País Basco (Espanha), este artigo afirma a importância do ócio nas sociedades contemporâneas e a necessidade de educar o público em e para o ócio, criando as condições de possibilidade adequadas para que o ócio se torne num verdadeiro instrumento impulsionador do desenvolvimento pessoal e social.
\end{abstract}

Palavras-chave: Ócio; itinerário de ócio; desenvolvimento humano; envelhecimento satisfatório; educação do ócio.

\section{A experiência de ócio e os fatores que a compõem}

Com o aprofundamento do estudo de ócio, torna-se claro que o seu valor não acaba com as noções do tempo e da atividade. Apesar da sua importância, as duas noções

\footnotetext{
* Tradução: Andrei Manoliu e Maria Elena Ortiz Revisão: Silvana Costa

${ }^{6}$ Este artigo foi desenvolvido no âmbito da investigação "Formação para um lazer experiencial valioso ao longo da vida: contribuição dos itinerários de ócio para um envelhecimento satisfatório" (ITINERE) financiada na última chamada do Programa Nacional de I+D+i (2012), pela Secretaria do Estado para Investigação, Desenvolvimento e Inovação no âmbito do Ministério da Economia e Competitividade, referindo EDU2012-38052.
} 
omitem a influência decisiva que a pessoa exerce no processo de conversão de um determinado tempo livre concreto e de uma determinada atividade, numa experiência de ócio. Convencidos da parcialidade destas abordagens, a investigação do Instituto de Estudos de Ócio da Universidade de Deusto defendeu desde o seu início no final dos anos 80 que o ócio é, antes de tudo, uma experiência pessoal, ou seja, é uma experiência complexa (direcional e multidimensional), focada em atuações queridas (livres e satisfatórias), autotélicas (com um fim autónomo) e pessoais (com implicações individuais e sociais) (Cuenca, 2006:14). Assim entendido, o ócio entra profundamente no reino do subjetivo e adquire uma infinidade de expressões, intensidades e significados que tornam o ócio num fenómeno mais rico, mas, sem dúvida, aumentam os desafios do seu estudo.

A atitude, a perceção e a interpretação são, para muitos autores que compartilham essa definição do ócio como uma experiência subjetiva (Neulinger, 1980; Tinsley \& Tinsley, 1986; Kleiber, Walker \& Mannell, 2011), três aspetos fundamentais para compreender o significado da experiência. A atitude refere-se a uma disposição positiva para o ócio, que capta um certo espírito de curiosidade, inquietação e interesse que funciona como um motor de ligação entre o comportamento e a ação. Enquanto a atitude nos aproxima do ócio através de uma maneira concreta de ser e de estar de acordo com as circunstâncias, a perceção torna-nos mais conscientes das nossas ações e das suas consequências, ao serem entendidas como atos de livre-arbítrio. No ócio, a pessoa vê-se como a causa das suas ações, enquanto dota a experiência de sentido, garantindo assim o seu significado pessoal. Então entende-se que, deste ponto de vista, a atividade de ócio escolhida (a pintura, o canto, a corrida ou a natação) possui um valor secundário em relação ao significado que a pessoa lhes dá. Por sua vez, a interpretação é o exercício cognitivo através do qual uma pessoa dá sentido à sua experiência de ócio. Esta interpretação é a principal responsável por que, em duas situações idênticas, a pessoa experimente emoções e sensações radicalmente diferentes; apenas através de diferenças de interpretação que separam as experiências de ócio das que não são e, portanto, o significado atribuído a cada um deles, podemos entender que, numa situação de risco causada por um acidente de avião inesperado, o seu protagonista seja vítima de pânico, enquanto em outra, escolhida pelo próprio sujeito e enquadrada por exemplo numa situação de desporto de risco, saltar do mesmo avião gera sensações de prazer e de satisfação irrepetíveis.

O ócio não é um tempo, mas sim uma experiência propiciada por um estado mental que me permite desfrutar de algo que os outros, talvez, não desfrutem. É uma área 
específica humana que faz com que nos sintamos livres, desprendidos e dispostos a atuar só pelo facto de que tal nos da satisfação. (Cuenca, 1995: 55)

Os estudos realizados ao longo das últimas três décadas do século XX a partir da Psicologia do ócio focaram a atenção em três aspetos essenciais para explicar o ócio em termos de experiência: a perceção da liberdade e a motivação intrínseca, como fatores condicionais da experiência, que a podem favorecer ou dificultar; e a satisfação, como uma das principais consequências que podem derivar da experiência de ócio (Neulinger, 1980; Iso-Ahola, 1980, Kelly, 1990, Kleiber, 1999; Csizskentmihalyi, 2000; Monteagudo, 2008, 2011; Cuenca Amigo, 2012a, 2012b; Kleiber, Walker \& Mannell, 2011; Rubio, 2012).

\subsection{Liberdade Percebida}

A sensação de liberdade percebida ocorre quando a pessoa que vive a ação de ócio a interpreta como resultado do seu livre arbítrio. O ócio há de ser percebido como resultado de uma escolha livre, de modo que a pessoa se veja como responsável tanto pelo seu comportamento como pelas consequências que provoca. O significado dessa liberdade não consiste numa liberdade completa - além disso, impossível para os seres humanos -, mas para ser assim percebida, para que a pessoa tenha a sensação de escolha, entre as diferentes opções, aquela que se enquadra melhor aos seus desejos e preferências. Para estes autores, a sensação de liberdade é a pedra angular do ócio, uma vez que o torna num espaço ideal para experimentar a sensação de controlo e autodeterminação que é inerente ao ser humano. Considerando os pressupostos básicos da teoria de Atribuição, o ócio, através deste poder de escolha, incentiva um estilo de atribuição interno em que o locus de controlo recai sobre o indivíduo, que se percebe a si próprio como uma causa direta das suas decisões e ações em relação ao ócio. Ter a noção da importância dessa sensação de liberdade é crucial do ponto de vista do ciclo de vida, pois a vida de um indivíduo é marcada por circunstâncias pessoais e sociais que atuam em detrimento desta sensação de liberdade e que, como consequência, podem impedir que muitas ações ou situações potenciais de ócio não sejam sentidos como tal.

A liberdade percebida está intimamente relacionada com a motivação que incentiva o ócio, de modo que quanto maior seja a sensação de liberdade que uma pessoa tem, maior será a sua orientação intrínseca para o ócio. 


\subsection{Motivação Intrínseca}

O ócio é um dos poucos comportamentos humanos que são caracterizados pela ausência de instrumentalização. O ócio tem um caráter não-utilitário, porque as suas ações não perseguem um fim externo, mas tornam-se num fim em si mesmas, e constituem o principal argumento da ação. Assim, o ócio também é uma das poucas áreas da vida nas quais não é necessário racionalizar o nosso comportamento. A busca de argumentos para justificar os comportamentos de ócio remete-nos de volta à ação, uma vez que esta não é um meio para atingir um fim, mas o próprio prémio. $\mathrm{O}$ autotelismo que carateriza o ócio reside na orientação intrínseca da sua ação.

Deci é um dos autores que defende a importância da motivação intrínseca como motor do comportamento humano. Com base nos pressupostos da sua Teoria de Autodeterminação enfatiza a orientação intrínseca do ser humano para comportamentos que permitam responder a necessidades básicas, tais como a necessidade de competência, autonomia e relações interpessoais (Deci \& Ryan, 2000). O ócio manifesta-se como um âmbito propício para responder a tais motivos internos, cuja consecução constitui uma grande parte da origem do comportamento de ócio. Para Deci, a orientação intrínseca do ócio contribui para o aumento da sensação de autodeterminação, não só pelos atributos pessoais da escolha de ócio, mas também através da perceção de si mesmo como um agente causal dos resultados de seus comportamentos de ócio. Assim, a satisfação que gera o sentimento de autodeterminação acrescenta-se ao causado pelo sentimento de competição que emana da maioria dos comportamentos de ócio: Subjacente a muitos dos comportamentos de ócio, um desafio de pesquisa - com outras pessoas ou por conta própria -, e de superação, que quando é satisfeito, promove uma sensação de competição que nos faz sentir competentes, connosco e com outras pessoas.

Os autores que se aprofundaram no estudo da motivação (Maslow, 1975; Beard \& Raghed, 1983, Weissinger \& Bandalos, 1995) destacam a importância de orientar a motivação contra motivos intrínsecos perante comportamentos de ócio incentivados por fatores externos. Os reforços externos, dirigidos inicialmente para fortalecer e continuar a participação podem ter efeitos contrários ao longo prazo, que acabam por prejudicar a motivação intrínseca (Lepper, 1973), enquanto os motivos intrínsecos, como a sensação de competição, mesmo depois de acabados, mantêm-se e aumentam a atração e o interesse que o ato de ócio desperta no indivíduo.

Como mencionado antes, conclui-se a existência de possibilidades reais de intervir para orientar os estilos motivacionais de pessoas para fins internos que garantam a 
continuação da participação no ócio. Também não se pode esquecer que a motivação é uma construção dinâmica que, tal como o ócio, pode experimentar mudanças causadas por fatores externos e internos (Deci \& Ryan, 2000). Especificamente, o envolvimento numa ação de ócio que é descoberta como fonte de satisfação e que inicialmente, não foi percebida como tal, pode fazer com que uma motivação inicial focada em motivos extrínsecos (restaurar a saúde, melhorar a imagem...) seja orientada por motivos intrínsecos mais ligados ao desfrute que vem da própria ação, e não aos resultados esperados dela.

\subsection{Satisfação}

O papel importante da liberdade percebida e a motivação intrínseca como fatores determinantes da experiência de ócio não devem esconder, no entanto, um elemento que dá sentido e atribui ao ócio a sua verdadeira razão de ser: a satisfação que promove. É o primeiro e mais básico dos benefícios que pode obter-se do ócio. Trata-se de uma sensação subjetiva de alegria, bem-estar e felicidade que é atribuída e entendida normalmente como resultado da ação de ócio realizada. Na literatura tradicional, estuda-se este constructo entendido de preferência como consequência dos comportamentos de ócio. Uma abordagem cronológica de experiência de ócio, dirigida a três momentos que parecem cruciais nela, - antes, durante e depois -, colocaria a satisfação ou o prazer no durante e no depois, como sentimento que acompanha a experiência e permanece associado a recordações alegres do mesmo. No entanto, esta abordagem habitual não substitui o papel potencial da satisfação antes de a experiência ocorrer. De facto, antes da ação - a sua preparação, a sua antecipação cognitiva, a configuração das expectativas em torno dela - são normalmente uma fonte de satisfação e de prazer que precede a ação (Cuenca, 2004).

O conceito de satisfação a que nos referimos aqui não deve ser confundido com a noção de prazer, a natureza homeostática ou com o senso de diversão. Ambos os aspetos são tão lícitos como importantes para o ser humano, no entanto, não são um reflexo autêntico do potencial do ócio nem das suas possíveis contribuições para a condição humana. A satisfação de que falamos é experimentada pela capacidade que o ócio tem em resposta a necessidades inatas que o ser humano tem, mudar, crescer, melhorar e superar. O ócio imprime sentido à vida através da sua capacidade de nos fazer sentir vivos, pessoas de valor, em estado de progresso permanente.

Estamos de acordo com Csikszentmihalyi (2000), quando afirma que admitir a liberdade percebida e a motivação intrínseca como elementos fundamentais da experiência subjetiva de ócio é insuficiente para lidar com o fenómeno em toda a sua 
magnitude, pois evidencia um dos seus principais impactos; o que confere o seu valor final: ser uma fonte de satisfação e caminho para a felicidade através do desenvolvimento pessoal que deriva da sua experiência. Se não fosse assim, ações que reúnem, a priori, os fatores determinantes do ócio: a liberdade percebida e a motivação intrínseca, tais como os comportamentos aditivos de jogo ou de uso de drogas, poderiam ser consideradas como ócio. Autores como Tinsley \& Tinsley (1986), Cuenca et al. (2010), Stebbins (2000, 2012) partilham esta opinião, e afirmam que para poder falar do ócio, é necessário que os comportamentos em causa envolvam experiências satisfatórias, culturalmente aceites e positivas para o sujeito, em termos de crescimento, maturidade e desenvolvimento pessoal.

\section{Diferentes formas de abordagem ao ócio}

Neste ponto de reflecção, as contribuições dos diferentes autores sugerem que nem todas as práticas de ócio contribuem da mesma forma para o desenvolvimento pessoal. Para Csikszentmihalyi (2000), o problema do ócio é que "não temos as destrezas incorporadas para fazer uso do tempo livre de forma satisfatória " (Csikszentmihalyi, 2000:23). Entende que só o tempo livre não é agradável, de modo que a única possibilidade de transformá-lo em uma fonte de prazer e crescimento é aprender com as fases iniciais da vida e preencher esse tempo livre corretamente. As experiências de ócio não ocorrem espontaneamente, mas, "para beneficiar de um desenvolvimento ótimo, uma pessoa deve aprender a aumentar a sua complexidade psicológica no tempo livre..." (Csikszentmihalyi, 2000:29). Segundo este autor, "desperdiça-se o tempo livre a não ser que melhore a complexidade psíquica. E, já que o tempo é o meio através do qual a vida se desdobra diante de nós, desperdiçar o tempo significa desperdiçar a nossa própria vida. Em vez de criarmos um eu mais complexo, navegamos numa travessia de mínimo desenvolvimento que a biologia e a cultura têm programado para nós." (Csikszentmihalyi, 2000:25). Para este autor, as divergências do ócio, a partir do ponto de vista da sua contribuição para o desenvolvimento humano, reside no grau de complexidade psicológica dos mesmos. As experiências em que prevalece o entretenimento como simples forma de dar substância ao tempo livre, e em uma atitude de receção passiva ou uma mínima implicação intelectual, são, certamente, uma maneira de se aproximar ao ócio. Mas para Csikszentmihalyi, isso não é nem a única nem a melhor maneira de experimentar o ócio. É talvez a maneira mais fácil e mais conveniente, uma vez que o grau de envolvimento se correlaciona positivamente não só com a satisfação que promove, mas também com o esforço, empenho e a constância com que uma pessoa se envolve no seu ócio. Assim, um ócio que requer envolvimento e comprometimento, dedicação e superação tem mais potencial para ser um ócio mais 
completo, mais maduro, a ser também um ócio psicologicamente mais complexo e mais satisfatório. O ócio que este autor afirma ser fator de desenvolvimento pessoal é um ócio que exige introspeção, reflexão, ação empenhada, consistência, formação em termos de aquisição de competências e habilidades.

Consequentemente, a aproximação ao ócio pode ocorrer de várias maneiras que variam de uma experiência focada no entretenimento ou diversão, até a experiência mais completa e satisfatória, perto do ócio entendido como um elemento de autorrealização e desenvolvimento pessoal. A procura do prazer é o denominador comum e o de ponto partida do ócio. Mas a origem e a complexidade das causas de diversão, assim como o seu impacto sobre a pessoa, é o que varia de uma experiência para outra. Com base no anterior, pode afirmar-se, que quanto maior a complexidade que podemos incorporar e atender com sucesso nas nossas práticas de ócio, maiores serão as probabilidades de ter experiências de ócio valiosas, capaz de transformar o ócio num fator de desenvolvimento pessoal e social.

\section{Gráfico 1: Formas de aproximação ao ócio em função da experiência}

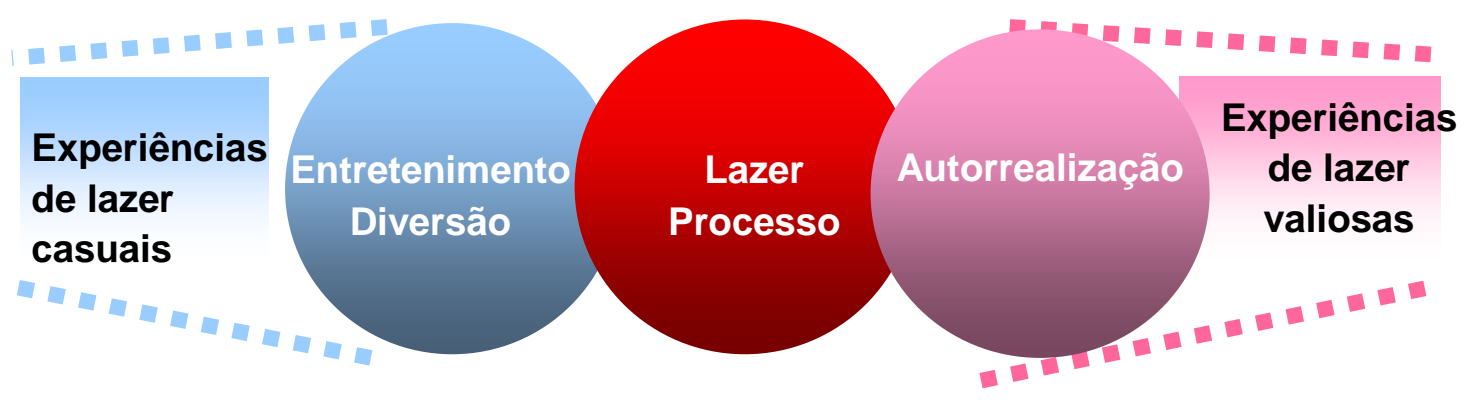

Fonte: elaboração própria.

No entanto, a incorporação dessa complexidade com a finalidade de desenvolver um ócio além do mero entretenimento, não surge espontaneamente, mas como resultado de um processo que leva tempo e dedicação, no qual a pessoa se tem ido preparando, consciente ou inconscientemente, para experimentar o ócio de uma forma mais completa. Durante esse processo, a pessoa terá tido a oportunidade de adquirir certas habilidades, ampliar os seus conhecimentos, desfrutar de experiências agradáveis e de outras, menos agradáveis, para ultrapassar desafios, etc. Portanto, de um ponto de vista sincrónico que mantem a sua atenção no desenvolvimento de uma atividade específica, o ócio deve ser entendido como um processo que pode envolver uma evolução, uma maneira pela qual a pessoa terá a oportunidade de passar de um ócio casual, centrado na diversão a um mais valioso na medida em que o seu nível de proficiência da 
atividade pode levar a sentimentos de autorrealização e crescimento pessoal. No entanto, o estudo científico do ócio não deve apoiar o seu discurso unicamente e de forma isolada num ponto de vista transversal focadas em cada uma das experiencias de ócio do individuo, mas deve priorizar um ponto de vista longitudinal, que vê o ócio como um projeto inacabado que se manifesta ao longo da vida e que pode e deve acompanhar a pessoa durante as várias fases da vida.

Ao assumir o caracter processual do ócio a partir de uma abordagem do ciclo de vida, torna-se necessária a observação e a integração de diversos comportamentos de ócio de um indivíduo com uma abordagem holística, capaz de fornecer uma visão geral da trajetória do ócio de uma pessoa. A partir desta perspetiva, o conceito de itinerário de ócio é especialmente inovador e valioso ao permitir a explicação de como são construídas as histórias de ócio a partir das decisões que as pessoas tomam em cada momento do ciclo de vida e as experiências que estas promovem.

Aqueles que se dedicam ao estudo do ócio sabem que nem todos os itinerários de ócio são igualmente valiosos do ponto de vista da contribuição para o desenvolvimento humano. Assim, devem conhecer-se quais são os fatores especialmente envolvidos na configuração dessas histórias de ócio que fazem com que um ócio experiencial valioso se torne num objetivo principal para a comunidade científica. Tal conhecimento permitir-nos-ia intervir de forma adequada em cada momento do ciclo de vida para modelar as trajetórias de ócio, evitando em cada período os fatores que afastam a pessoa de processos de crescimento pessoal, incentivando aqueles que são instrumentos impulsionadores de crescimento através de um ócio experimental valioso.

Os parágrafos que se seguem permitem-nos aprofundar a construção itinerária do ócio e esclarecer as suas principais contribuições para o estudo do ócio como fator de desenvolvimento pessoal e social.

\section{O conceito do itinerário de ócio e a sua contribuição para o estudo do ócio como fator de desenvolvimento humano}

O conceito itinerário de ócio refere-se à trajetória de ócio que a pessoa desenvolveu ao longo de sua vida; recebe, portanto, o conjunto de experiências de ócio que foram desfrutadas ao longo da vida. De seguida encontra-se a definição de "itinerário" de Masnou e Puig, um itinerário de ócio "inicia-se no momento em que o sujeito entra em contacto com o ócio (cultura, turismo ou desporto), é desenvolvido durante um período mais ou menos prolongado que é dedicado à prática de uma ou de mais práticas de ócio e acaba quando se abandonam todas as relações com esta área como um participante” (adaptado de Masnou \& Puig, 1995:371). 
Este conceito, herdado da Sociologia do desporto, faz-nos pensar no ócio como um caminho que se vai completando à medida que avançamos, cada vez que escolhemos livremente, agimos, sentimos e voltamos a pensar qual será a nossa próxima participação no ócio. Cada uma das fases pelas quais este caminho decorre adquire um sentido, um significado e um valor diferente para o indivíduo, cumpre umas funções e deixa uma marca diferente na pessoa. Estas fases são normalmente representadas em três momentos distintos:

- o início (I), que tem lugar no momento em que a pessoa inicia a sua relação com o ócio;

- o desenvolvimento, no qual a interação da pessoa com o ócio pode tomar diferentes direções, optando pela continuidade (C) de todas ou de algumas das suas práticas, o abandono temporário de outras, de modo que não implica uma rutura definitiva visto que se recuperará novamente através de reinícios (R) ou a substituição (S) de umas atividades por outras;

- e, finalmente, a resolução do itinerário, com o que a pessoa põe fim à sua participação no ócio por meio de decisões de abandono definitivo (A).

Diferentes teorias, entre as quais se destacam as elaboradas a partir da abordagem do Ciclo Vital, procuram a existência de um padrão ou de uma tendência dominante na evolução do ócio ao longo da vida. Uma das teorias mais suportadas é a teoria do Desenvolvimento do Ócio (Iso-Ahola, 1980). O seu princípio central afirma que a configuração dos itinerários é fortemente marcada pela evolução dinâmica de ócio, na qual as pessoas procuram constantemente o equilíbrio entre a tendência face à comunidade e a procura de mudança, através das suas escolhas e comportamentos de ócio. Apesar dessa bipolaridade inerente à natureza do ócio, vários estudos apontam a importância da familiaridade e da satisfação obtida das experiências de ócio passadas como motores fundamentais na tomada de decisões do ócio (Agahi, Ahacic \& Parker, 2006). Assim, confirma-se a tendência de continuidade que condiciona os itinerários do ócio; de tal maneira que a história do ócio já experimentada torna-se numa base sólida para delinear a trajetória futura do ócio de uma pessoa.

Existem vários estudos que sugerem que metade das atividades de ócio de uma pessoa adulta tem uma atividade ou expressão de ócio equivalente aos padrões de ócio que o indivíduo teve durante a infância (Iso-Ahola, Jackson \& Dunn, 1994:229). Se de facto uma percentagem significativa das atividades que constroem os padrões de ócio de uma pessoa adulta tem a sua origem nas atividades, cujas preferências são desenvolvidas durante a infância, estamos perante uma informação com amplas implicações desde o 
ponto de vista da política, gestão e intervenção educativa na matéria do ócio. Se o objetivo é aumentar o valor do ócio como fator de desenvolvimento pessoal e social ao longo da vida, não se pode ignorar a importância de expor às pessoas desde idades precoces para uma ampla gama de possibilidades de ócio que lhes permitam perceber as potencialidades de ócio, criando inquietação, expectativas e habilidades necessárias para perseguir e alcançar um ócio de qualidade nas etapas posteriores da vida.

Em síntese, o estudo dos itinerários de ócio abre o caminho para a educação do ócio ao ratificar que o processo através de qual o ócio de uma pessoa aproxima-se de um ócio experiencial valioso não é por acaso ou espontaneidade, mas é um processo formativo no qual se vão abrir novos horizontes, capazes de converter o ócio num fator de desenvolvimento humano. Consiste na preparação das pessoas para que não se adaptem a um ócio dirigido ao entretenimento, à diversão ou a trazer sentido ao passar dos dias, e que procurem o acesso a experiências de ócio que os imergem em processos de melhoria e de crescimento pessoal (Monteagudo \& Cuenca, 2012).

O estudo dos itinerários de ócio podem desempenhar um papel fundamental para o alcance deste objetivo, ajudando a definir quais os padrões evolutivos mais favoráveis para o avanço a um ócio valioso, quais os fatores que preparam o caminho para o desenvolvimento pessoal através do ócio e, acima de tudo, quais as opções existentes para intervir para orientar e/ou reorientar as trajetórias do ócio para o caminho mais adequado para chegar ao objetivo proposto. $\mathrm{O}$ valor perspetivado baseado no conceito de itinerário torna-se a principal atração para investigadores e profissionais que percebem a partir deste conceito uma nova maneira de entender a evolução dinâmica de ócio, definindo fases, esclarecendo tendências e padrões de mudança no caso de investigadores; e numa estratégia adequada tanto para a melhor adaptação das preferências e possibilidades mutáveis como para otimizar os benefícios dos seus programas de ócio, no caso de profissionais. Compreender o conceito itinerário é assumir, a priori, três questões fundamentais:

- A compreensão das práticas culturais, desportos, etc. como experiências de ócio que ao fazerem parte de um processo vital inacabado, pode adaptar diferentes expressões e significados nas diferentes fases da vida.

- A importância de perceber a qualidade das experiências que favorece a oferta de ócio existente mais do que a quantidade de práticas que a constituem.

- A necessidade de substituir o ponto de vista sincrónico e concreto planificado pela oferta do ócio, por outra, de natureza longitudinal, capaz de considerar e 
formar a oferta presente e futura, atendendo a evolução das preferências, motivações, necessidades e possibilidades da cidadania nas diferentes fases da vida.

Qualquer política de ócio, modelo de gestão ou intervenção nesta área não pode ser realizada apenas a pensar em como é realmente a cidadania e quais serão as suas exigências de ócio, é necessário conseguir, que a médio e longo prazo, transformar o ócio num espaço de estímulos orientados para o desenvolvimento pessoal e social.

\section{Contribuição dos itinerários de ócio para o desenvolvimento humano como chave do envelhecimento satisfatório: o caso dos idosos na comunidade autónoma do País Basco (Espanha)}

Tendo em conta tudo o anterior, uma das últimas investigações a serem realizadas nos Estudos de Ócio da Universidade de Deusto, no amparo da última convocatória do Programa Nacional I+D+i (2012) do Ministério da Economia e Competitividade espanhol, tem como principal objetivo esclarecer as principais contribuições dos itinerários de ócio no desenvolvimento humano com base no conhecimento dessas histórias de ócio que torna mais viável um ócio experiencial valioso. Este estudo, focado num grupo de pessoas idosas com idades entre 61 e 75 anos $^{7}$, analisa o impacto do ócio no envelhecimento satisfatório. À luz dos resultados preliminares que alimentam a primeira fase desta investigação, apresentamos de forma breve algumas conclusões relevantes relacionadas com o âmbito do País Basco, por suas implicações no estudo dos itinerários de ócio.

\subsection{Significado do Ócio}

O ócio mostra-se essencialmente valioso entre aquelas pessoas para quem constitui uma fonte inesgotável de sentido vital. A utilização de respostas fortemente ancoradas na esfera emocional mostra a afeição, a significação pessoal e a plenitude com que o ócio é experimentado por algumas pessoas. Este grupo mostra um forte interesse intrínseco pela ação que alimenta o seu interesse por ela e explica a sua consideração do ócio como um fim em si mesmo. Esta compreensão do ócio contrasta com a de outras pessoas para quem esta área não parece ter a transcendência de casos anteriores. Prevalece neles um interesse extrínseco para a ação que enfatiza o valor instrumental do ócio como um recurso eficaz para preencher o tempo livre, combater o

\footnotetext{
7 Vid. "ITINERE. Formação para um ócio experiencial ao longo da vida. Contribuição dos itinerários de lazer para o envelhecimento bem sucedido" (EDU2012-38052)
} 
tédio ou a solidão. Os seus argumentos não apelam para o valor atribuído ao ócio, como tal, mas sim para as suas qualidades como impulsionador de outros objetivos aos quais orientam explicitamente a sua ação.

\subsection{Repertório de Ócio}

A população basca tem um repertório muito dinâmico e variado de práticas de ócio, não só em número de atividades, mas também numa variedade de domínios relacionados com as atividades realizadas (desporto, cultura, jogos, turismo, voluntariado, socialização, etc.). No entanto, comprova-se que uma elevada taxa de participação em atividades de ócio não é suficiente para alcançar um envelhecimento satisfatório. Ou seja, o mero ativismo não é o que afeta o envelhecimento satisfatório, mas sim a qualidade dessas práticas, e a capacidade do indivíduo para transformá-las em experiências valiosas, satisfatórias, duradouras e memoráveis. As atividades de ócio mais frequentemente praticadas não são aquelas que servem para definir a identidade dos seus protagonistas, ajudando-os nas suas realizações pessoais. Na verdade, há um défice revelador de envolvimento em atividades de ócio mais comuns. Isto sugere que o próprio conteúdo e natureza de certas atividades as torna mais prováveis, do que outras, de se tornarem "significativas", sendo específico delas que se lhes possa atribuir valores muito especiais à sua prática. Essas atividades são precisamente aquelas que permitem que o indivíduo marque desafios e avance na própria ação ao longo de um período de tempo prolongado, que exigirá do sujeito uma atitude criativa enquanto comprometida. Assim, parece claro que é a qualidade das práticas, e não a sua quantidade, que está no fator de promoção do envelhecimento satisfatório.

\subsection{Benefícios do Ócio}

Os benefícios que as pessoas percebem como resultado do ócio são diferentes dependendo se o ócio de que gostam é mais ou menos valioso do ponto de vista do desenvolvimento humano. As pessoas que desenvolveram formas valiosas de ócio percebem, melhor que os outros, os benefícios associados com a sensação de competência, o enriquecimento pessoal e o reconhecimento social. Para aqueles que não desenvolveram formas de ócio valiosas, os benefícios de ócio emergem do valor instrumental concedido à ação, de tal maneira que torna o ócio em instrumento para enfrentar ou ultrapassar os acontecimentos vitais de diferente índole (normativizados ou não) que podem desencadear situações de deterioração da saúde física e psicológica, especificamente relacionados a esses períodos do ciclo de vida (Hutchinson \& Kleiber, 2005). Nestes casos, os benefícios percebidos que prevalecem são estar ativo perante o uso do tempo livre, relaxar, fugir dos problemas pessoais ou estados de saúde 
delicados, entre outros. O sentimento de satisfação, o cultivo ou ampliação do círculo social ou o aumento da coesão familiar são também benefícios recebidos pelos idosos, mas que não discriminam entre formas de ócio mais ou menos valiosas.

\subsection{Itinerários de Ócio}

O estudo das pessoas idosas do País Basco permitiu a identificação de quatro itinerários, obtidos a partir da interseção de três critérios fundamentais: o período vital da gestão da(s) preferência(s), o período vital do início da(s) prática(s) de ócio e da presença ou ausência de inovação no processo evolutivo da(s) prática(s). A intersecção desses três critérios resultou em quatro vias principais:

\section{- Itinerário 1. Primeiros descobridores e seguidores (25\%).}

Completam este itinerário as pessoas com atividades de ócio, cujos interesses surgiram durante a infância, começaram a sua prática durante esse mesmo período e continuaram a prática da atividade original sem incorporar mudanças até à terceira idade. Vale a pena destacar que a implementação dessas práticas remonta à infância e não deixaram de ser praticadas desde então.

\section{- Itinerário 2. Descobridores precoces procrastinadores (15\%).}

Este itinerário acolhe pessoas cujo interesse pelas atividades de ócio começaram na infância, mas não iniciam a prática real até etapas posteriores; seja na juventude ou na terceira idade. No entanto, uma vez iniciada a prática, esta contínua na terceira idade.

\section{- Itinerário 3. Descobridores precoces inovadores (15\%).}

Trata-se de pessoas idosas que também começam a mostrar interesse durante a infância por um campo concreto de ócio (cultura, desportos...); começam durante a infância uma ou mais atividades associadas a essa área de interesse, para posteriormente serem abandonadas e substituídas por outra atividade que persiste até a terceira idade e que é precisamente a atividade selecionada como mais significativa. Todas as práticas reunidas por este itinerário pertencem ao âmbito da cultura, com uma forte dimensão criativa, tal como a escrita de poesia ou cantar num coro. A inovação toma forma neste itinerário através da presença de alterações que vão modelando as atividades de ócio com os interesses, aptidões e possibilidades de mudanças de quem as protagonizam. 


\section{- Itinerário 4. Descobridores tardios (45\%).}

Trata-se de pessoas que começam a ter interesse na idade adulta ou na terceira idade por uma prática de ócio que acaba por ser para eles a mais significativa. Cozinhar, viajar, tirar fotografias, praticar tai chi, leitura e formação através de cursos de natureza cultural fazem parte das atividades que se qualificam para este padrão de desenvolvimento. A inovação, inerente a este itinerário, é evidente através da abertura de novas áreas de interesse demonstradas por pessoas designadas para este grupo. A importância deste itinerário não está apenas nos factos quantitativos (sendo o mais numeroso), senão também nos aspetos qualitativos que demonstram a relevância da pesquisa de mudanças entre as pessoas mais velhas e, acima de tudo, uma atitude de abertura para à experiência que é fundamental para continuar a crescer durante a fase tardia da vida.

\section{Conclusões}

Os resultados do estudo de caso apresentado permitiram tirar algumas conclusões importantes devido às suas implicações na hora de planificar, gerir, programar ou participar no ócio, com o propósito de otimizar as potencialidade deste fenómeno para o desenvolvimento pessoal e social.

1. Do ponto de vista do envelhecimento satisfatório, torna-se claro que não é o mesmo desfrutar de um ócio altamente valioso do que desfrutar de um ócio que não é concebido como tal. A diferença é que o primeiro se torna num inestimável gerador de sentido vital e canal de enriquecimento pessoal.

2. A possibilidade de atingir um ócio valioso entre as pessoas idosas não é estranho para a trajetória de ócio anterior visto que o seu repertório de ócio atual, o significado, a importância e os benefícios que lhes são atribuídos são o resultado de um processo vital de construção em que o ócio dialoga de maneira persistente com o resto das esferas da vida e avança tendo em conta as várias circunstâncias pessoais e sociais sobre as quais são sustentados os itinerários de ócio.

3. Segundo o anterior, investir no ócio a partir de idades precoces é investir nas pessoas e no desenvolvimento ideal das suas potencialidades, preparando as bases para tornar viável o acesso a um ócio de qualidade, para além do mero entretenimento ou diversão. A educação em geral e de ócio, em especial, são ferramentas inquestionáveis para equipar as pessoas com os recursos necessários para que possam transformar as suas práticas de ócio em experiências valiosas. 
4. O ócio experiencial valioso foge do ativismo para realçar a qualidade e quantidade das práticas de ócio. Nem todas as práticas de ócio parecem oferecer o mesmo horizonte de possibilidades para o desenvolvimento pessoal. A partir de uma perspetiva diacrónica que vai além da aparência sincrónica habitual do ócio, tornam-se particularmente interessantes as atividades cuja natureza oferece, a quem as pratique, a possibilidade de marcar desafios a médio/longo prazo e melhorar no desenvolvimento progressivo da ação, e retroalimentando assim o interesse intrínseco pela ação desenvolvida e a sua adesão à mesma.

5. É necessário ter em conta a importância da evolução dinâmica do ócio, em que a tendência para a continuidade convive com a orientação para a mudança ao longo da vida. Esta dupla orientação na configuração de itinerários de ócio devem ser levados em conta em cada fase da vida, eliminando ideias preconcebidas que restringem a inovação e a orientação na fase infantil e juvenil. Em termos operacionais, deve-se realçar, portanto, a importância de promover ao longo da vida e também entre os idosos novos horizontes interessantes como potenciais geradores de significado e de crescimento pessoal (Cuenca, Aguilar e Ortega, 2010).

6. A componente social do ócio é uma condição necessária, mas não suficiente para o desenvolvimento de formas de ócio valiosas. A disponibilidade de um círculo de amizades é concebida em si mesmo como um dos benefícios mais importantes do ócio em resposta a uma das necessidades psicológicas básicas: o sentimento de pertença. O cuidado e a expansão das amizades é geralmente relacionada a um aumento na autoestima, porque a pessoa sente a apreciação e aceitação do seu círculo social. No entanto, desfrutar de um ócio com uma forte componente social não é suficiente para desenvolver formas valiosas de ócio. Embora a ausência desta componente social seja uma barreira importante para o ócio valioso, a sua presença não garante o seu desenvolvimento. Por isso não encontramos nenhuma manifestação de ócio valioso que careça de um círculo social nutrido, mas nem todas as pessoas que têm esse círculo avançaram para formas valiosas de ócio.

7. Relevância da aprendizagem e a formação ao longo da vida.

A aprendizagem, amparada no sentimento de competição, é um dos grandes motores do comportamento de ócio e, portanto, fundamental na construção dos itinerários de ócio, cuja direção varia de acordo com as decisões de ócio tomadas a cada momento. $\mathrm{O}$ ócio que envolve uma aprendizagem adequada às possibilidades de cada pessoa é sempre um desafio que, orientado adequadamente, proporciona uma grande gratificação. Da mesma forma, é fundamental a aproximação e a 
promoção de formas de ócio valiosas ao amparo de figuras externas, responsáveis por espalhar o seu entusiasmo para o ócio e orientar o processo de aprendizagem dos outros, fornecendo-lhes recursos adequados que lhes permitam continuar a imersão em processos de crescimento pessoal por conta própria. Verifica-se, portanto, que no contexto de ócio, o binómio da aprendizagem-formação é, obviamente, uma das fontes de satisfação pessoal mais poderosas e que mais contribui para a imersão da pessoa em processos de mudança e crescimento pessoal. É, portanto, uma via de aproximação para um ócio valioso.

Definitivamente, o conceito do itinerário de ócio revela-se, à luz da investigação, como uma ferramenta válida para o estudo longitudinal do ócio ao longo da vida. Por um lado, pela sua adequação aos pressupostos teóricos em que se baseia esta pesquisa sobre o ócio: o valor experimental e o seu caráter processual. Mas também pela sua capacidade de identificar os fatores impulsionadores de um ócio experiencial valioso, estabelecendo assim as bases para futuras intervenções que ajudam a consolidar o papel do ócio como fator de desenvolvimento humano.

\section{Referências Bibliográficas}

AGAHI, N; AHACIC, K \& PARKER, M. (2006). Continuity of participation from middle age to old age. Journal of Gerontology, 61, 340-346.

BEARD, J.G. \& RAGHED, M.G. (1983). Measuring leisure motivation. Journal of Leisure Research, 15, 219-228.

CSIKSZENTMIHALYI, M. (2000). Ocio y creatividad en el desarrollo humano. Em M. CSIKSZENTMIHALYI; M. CUENCA; C. BUARQUE \& C. TRIGO et al. Ocio y Desarrollo. Potencialidades del ocio para el desarrollo humano (pp. 17-32). Documentos de Estudios de Ocio, 16. Bilbao: Universidad de Deusto.

CUENCA AMIGO, M. (2012a) (ed.): "Reflexiones sobre el ocio en el siglo XXIReflections on eisure in the twenty-first century". Madrid: ARBOR-CSIC, Vol. 188, 754. Marzo-Abril 2012.

CUENCA AMIGO, J. (2012b). El valor de la experiencia de ocio en la modernidad tardía. Documentos de Estudios de Ocio, 48. Bilbao: Universidad de Deusto.

CUENCA, M. (2004). El ocio como experiencia humana. ADOZ. Revista de Estudios de Ocio, 28. 15-18.

CUENCA, M., (coord.) (2006). Aproximación multidisciplinar a los Estudios de Ocio. Documentos de Estudios de Ocio, 31. Bilbao: Universidad de Deusto.

CUENCA, M., AGUILAR, E. Y ORTEGA, C., (2010). Ocio para innovar. Documentos de Estudios de Ocio, 42. Bilbao: Universidad de Deusto. 
DECI, E.L. \& RYAN, R.M. (2000). The "what" and "why" of goal pursuits: Human needs and self-determination of behaviour. Psychological Inquiry, 11, 227-268.

HUTCHINSON, S. L. \& KLEIBER, D. A. (2005). Leisure, constraints, and negative life events: Paradox and possibilities. Em: E. L. Jackson (ed.), Constraints to leisure (pp. 137-150). State College, PA: Venture.

ISO-AHOLA, S. (1980). The social psychology of leisure. Dubuque: William Brown.

ISO-AHOLA, S.; JACKSON, E. \& DUNN, E. (1994). Starting, ceasing and replacing leisure activities over the lifespan. Journal of Leisure Research, 26, 227-249

KLEIBER, D. A. (1999). Leisure experience and human development. A dialectical interpretation. New York: Basic Books.

KLEIBER, D.A.; WALKER, G.J. \& MANNELL, R.C. (2011). A social psychology of leisure ( $2^{\mathrm{a}}$ ed.). State College: Venture Publishing.

MASLOW, A. H. (1975). Motivación y personalidad. Barcelona: Sagitario

MASNOU, M. \& PUIG, N. (1995). El acceso al deporte: los itinerarios deportivos. Em D. Blázquez (ed.) La iniciación deportiva y el deporte escolar (pp. 371-394). Barcelona: Inde Publicaciones.

MONTEAGUDO, M.J. (2008). Reconstruyendo la experiencia de ocio: características, condiciones de posibilidad y amenazas en la sociedad de consumo. Em M.J. Monteagudo (ed.) La experiencia de ocio: una mirada científica desde los Estudios de Ocio (pp. 81-110). Documentos de Estudios de Ocio, 35. Bilbao: Universidad de Deusto.

MONTEAGUDO, M.J. (2011). Los itinerarios de ocio deportivo. Estudio de los jóvenes de Bizkaia (1995-2005). Bilbao: Universidad de Deusto. Tesis Doctoral.

MONTEAGUDO, M.J. \& CUENCA, M. (2012). Los itinerarios de ocio desde la investigación: tendencias, retos y aportaciones. Revista interuniversitaria de Pedagogía social, Tiempos educativos, tiempos de ocio. núm. 20, Julio-septiembre 2012, pp. 103-136.

NEULINGER, J. (1980). The psychology of leisure. Springfield: Charles C. Thomas.

RUBIO FLORIDO, I. (2012). El tiempo de ocio de los cuidadores familiares: Su relación con la salud y percepción de carga. Tesis doctoral no publicada. Universidad de Deusto, Facultad de Ciencias Sociales y Humanas, Bilbao.

STEBBINS, R. A. (2000). Optimal leisure lifestyle: Combining serious and casual leisure for personal well-being. In M. Cuenca (Ed.), Leisure and human development: Proposals for the 6th World Leisure Congress. (pp. 101-107). Bilbao: University of Deusto.

STEBBINS, R. A. (2012). Compromiso temporal discrecional: efectos sobre la elección y el estilo de ocio. ARBOR-CSIC, vol. 188, 754, 293-300.

TINSLEY, H.E.A. \& TINSLEY, D.J. (1986). A theory of attributes, benefits and causes of leisure experience. Leisure Sciences, vol. 8 (1), 1-45. 
María Jesús Monteagudo é Licenciada em Psicologia e Doutorada em Ócio e Desenvolvimento Humano pela Universidade de Deusto (Bilbau, Espanha). É membro do Instituto de Estudos de Ócio desta Universidade desde de 1992 e faz parte da equipa de pesquisa interdisciplinar deste Instituto. Estuda o ócio de um ponto de vista psicossociológico e o fenómeno do desporto como experiência de ócio. É membro da Associação Espanhola de Investigação Social Aplicada ao Desporto (AEISAD), OcioGune, Rede Espanhola de Equipas de Investigação de Estudos de Ócio sobre Ócio e Desenvolvimento Humano e de OTIUM, Associação Latino-Americana de Estudos de Ócio.

mjmonte@deusto.es

Jaime Cuenca é licenciado em Filosofia e Doutorado em Ócio e Desenvolvimento Humano pela Universidade de Deusto. Atualmente, é professor na Universidade de Deusto, onde leciona no Mestrado em Gestão de Projetos de Ócio, Cultura, Turismo, Desporto e Recriação e no Mestrado em Organização de Congressos, Eventos e Exposições. Nos últimos anos tem trabalhado como assistente de pesquisa no Instituto de Estudos de Ócio. Pertence ao grupo de investigação sobre Ócio e Desenvolvimento humano, reconhecida pelo Governo Basco.

jaime.cuenca@deusto.es

Fernando Bayón é Doutorado em Filosofia pela Universidade de Deusto. Durante o Doutoramento frequentou a Universidade Eberhard Karls de Tübingen (Alemanha), onde estudou com Manfred Frank e ainda conseguiu ouvir Hans -Georg Gadamer. Fez estágios de investigação e pós-doutoramento em várias universidades internacionais Atualmente, é pesquisador no Instituto de Estudos de Ócio da Universidade de Deusto e está ligado a vários projetos de investigação no âmbito do Plano Nacional de I+D+i no CSIC (com Juan Carlos Velasco e José M. González García ). É autor de vários livros publicados.

fernandobayon@deusto.es

Douglas A. Kleiber é Doutorado pela Universidade do Texas, Estados Unidos da América. Foi professos em várias universidades mas atualmente desenvolve a sua atividade na Universidade da Geórgia (E.U.A.) como Professor e Investigador na área dos Estudos de Ócio e Recreação. É editor de várias revistas científicas, como a Leisure Studies, e faz parte da Academia das Ciências do Ócio. Entre os seus temas de investigação destacam-se: o Ócio ao longo da vida, Ócio na terceira idade, atividade de Ócio e desenvolvimento humano, o Ócio como recondutor da vida, a importância do Ócio na doença, Ócio e adolescência, os diferentes usos do Ócio segundo o género.

dkleiber@uga.edu 